\title{
The Response of South Western Railway to the COVID-19 Pandemic
}

\author{
Ross Liddell* \\ South Western Railway, South Bank Central, 4th Floor, 30 Stamford Street, London SE1 9LQ, UK
}

\section{ARTICLE INFO}

\section{Article History}

Received 12 December 2020

Accepted 15 March 2021

\section{Keywords}

COVID-19

railway

crisis

management

\begin{abstract}
Pandemic crisis management is not something that South Western Railway (SWR) has had to contend with previously. As a result of the introduction of a crisis management approach to the COVID-19 pandemic, the business has been able to continue operating and to continue safely serving the needs of its customers. Readers will be shown how COVID-19 was largely unknown in the UK and when it started to significantly affect the nation in March 2020, SWR rapidly had to introduce new processes and procedures to combat the virus and maintain high levels of customer and colleague safety. Readers will also be shown how SWR has constantly sought to innovate in all areas of its response to the pandemic and how this approach has brought benefits to the business.
\end{abstract}

(C) 2021 The Author. Published by Atlantis Press B.V.

This is an open access article distributed under the CC BY-NC 4.0 license (http://creativecommons.org/licenses/by-nc/4.0/).

\section{INTRODUCTION}

This report provides an overview of the response of South Western Railway (SWR) to the challenges presented by the COVID-19 pandemic and the objective of this report is to discuss the effectiveness of the response.

South Western railway like other train operators worldwide has been tested like never before. The closest comparison to this level of disruption is that caused by the Second World War.

The business has been tested on a number of fronts including initially high rates of COVID-19 related absenteeism and a significant drop in passenger numbers. The business has also attempted to ensure the highest level of COVID-19 safety possible for the business's colleagues and customers and to ensure the correct implementation of the UK Government's various COVID-19 requirements.

An additional challenge that was faced, particularly at the start of the pandemic, was the high degree of uncertainty around COVID-19. Key areas of uncertainty included how it would impact the country, how the Government would respond and how in turn train operators would have to respond.

The pandemic has had a significant, and long-lasting effect on how the economy of the UK operates, how people travel and how businesses operate.

The Confederation of British Industry [1] states that: "the coronavirus pandemic has had a dramatic impact on how people and businesses operate day-to-day, not least in how they approach travelling to and from places of work". This highlights the consequential

"Email: ross.liddell@swrailway.com demand reduction due to the way businesses have changed the way they operate.

The UK is not unique regarding the impact of COVID-19 on customer demand for travel. According to WSP using data from the Moovit platform [2], in the UK there has been an approximately $77 \%$ reduction in travel across all forms of public transport in urban areas. This figure is broadly comparable to other Western nations, for example Canada which has seen an approximately $75 \%$ reduction in the use of public transport. A key point to note is that while public transport use has dropped significantly in most Western economies, it has not dropped to the same extent as in many East Asian territories, for example in Hong Kong where public transport use has reduced by approximately one-third. It can be suggested that this is because these territories have had more experience in dealing with infectious disease outbreaks, e.g. Severe acute respiratory syndrome (SARS). Also, their economies, structures and processes are much more agile in responding to pandemics and there is a sense of "life carries on". It should be noted that SWR has liaised closely throughout the pandemic with MTR Corporation Limited, Hong Kong, learning from their experiences in dealing with infectious disease outbreaks.

\section{ABOUT SOUTH WESTERN RAILWAY}

Prior to the COVID-19 pandemic, SWR was one of the busiest commuter railways in Europe. SWR has a wide network stretching from London Waterloo to Weymouth, Exeter and Bristol in the West of England and Southampton and Portsmouth on the South Coast. Additionally, the business is responsible for the entire railway operation on the Isle of Wight, which is different from elsewhere in the UK where normally Network Rail (infrastructure operator) operates the fixed railway infrastructure. On the Isle of Wight, SWR operates all infrastructure, in addition to running train services. 
The business directly employs approximately 5300 individuals [3-6].

The majority of train operations in the UK are traditionally operated under a franchise, awarded by the UK Government's Department for Transport. FirstGroup MTR took responsibility for the SWR franchise in August 2017, with FirstGroup owning $70 \%$ of the business and MTR owning the remaining 30\%.

Additionally, the business has a diverse range of rolling stock, ranging from 1930s-era electric London Underground trains operated on the Isle of Wight, diesel 1980s stock and a range of other trains introduced over a number of years. The business eagerly awaits the arrival of new electric trains (the Arterio fleet) to service most of its suburban routes and substantially refurbished former London Underground trains to service the Isle of Wight.

\section{THE RESPONSE OF SWR TO COVID-19}

The following pages in this report show the various UK Government policies introduced with respect to COVID-19, readers will be shown in detail what the SWR response has been in key business areas, with a particular focus on ensuring business resilience, customer safety and colleague safety.

At the time of writing this report, the UK is currently experiencing a second wave of COVID-19 cases noting that the virus started to be observed in UK on the 31 January 2020 [7-10]. The "first wave" of COVID-19 cases was experienced in March and April [11,12].

The UK Government's stated policy has been:

"return to life as close to normal as possible, for as many people across the UK as possible, as fast and fairly as possible; in a way that avoids a new epidemic, minimises lives lost and maximises health, economic and social outcomes" $[11,12]$.

The timeline below highlights significant points related to COVID-19 in the UK and details the UK Government's response. Readers should note that since the initial UK wide lockdown, there has been divergence in the approach to the management of COVID-19 from the four home nations (England, Scotland, Wales, Northern Ireland) and the rest of this report focuses on the measures in place in England, given this is the jurisdiction SWR operates in.

- 31/1/20: First confirmed COVID-19 cases in the UK.

- 3/3/20: UK Government publishes its action plan for dealing with the virus, highlighting a variety of potential scenarios.

- 23/3/20: Given a significant reduction in customer revenue, the UK Government announces that existing rail franchise arrangements were being temporally suspended and transferred to an Emergency Measures Agreement.

- 23/3/20: UK Prime Minister Boris Johnson announces UK-wide emergency measures, with the public being ordered to remain at home and only to leave home for a very limited number of reasons.

- 25/3/20: British Transport Police (BTP) deploy significant amounts of extra officers to patrol the UK railway system, to discourage non-essential travel.
- 9/4/20: UK Government announces that the UK is starting to see an impact from the COVID-19 control measures introduced.

- 10/5/20: UK Government announces plans for a limited reopening of the UK economy.

- 28/5/20: BBC [7-10] reports that test and trace systems in England go live.

- 02/6/20: UK Office for National Statistics announces the number of COVID-19 deaths have been at their lowest level since March, as reported by the $\mathrm{BBC}[7-10]$.

- 15/6/20: The wearing of face coverings on public transport in England becomes law.

- 28/6/20: BBC [7-10] reports UK Government details that it is considering introducing a local lockdown in Leicester. This highlights a change in UK Government approach from national lockdown restrictions, toward local lockdown restrictions, based on case numbers.

- 24/7/20: The wearing of face coverings in public places in England becomes law.

- 1/8/20: Shielding programme for those that are classed as clinically extremely vulnerable is paused.

- 1/9/20: Schools in England begin reopening.

- 14/10/20: Tier regulations come into force; these define three levels of restrictions that will be applied based on COVID-19 case numbers.

- 5/11/20: 4-week national lockdown in England announced.

Figures 1 and 2 on the following page contextualise the overall COVID-19 situation at the time of writing this paper.

The information provided in Figures 1 and 2 from the UK Government has been included in this report to highlight the extent of the epidemic within the UK at the time of writing this report.

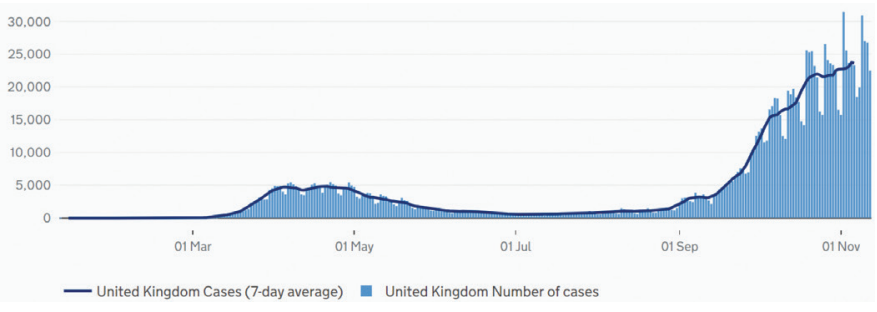

Figure 1 Number of positive COVID-19 cases in the UK.

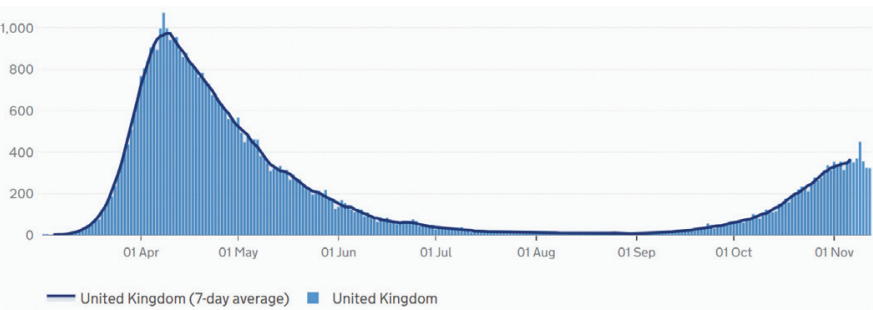

Figure 2 Deaths within 28 days of a positive COVID-19 case [11,12]. 
The importance of rail in the UK cannot be understated and that is why on 23 March 2020, the UK Government introduced Emergency Measures Agreements. These agreements transferred cost and revenue risk from operators of railway franchises to the UK Government to ensure continuity of operations. As reported by Sherratt [13], the Secretary of State for Transport stated that these agreements "ensure the railway can continue to react quickly to changing circumstances and play its part in serving the national interest".

It is the latter part of the Secretary of State's statement that underscores the importance of the railway system to the UK. If there had been an interruption to the operation of rail, there would have been severe national consequences, with key workers (health workers, emergency services, teachers, food supply chain workers etc.) unable to get into work. SWR has had to play an important role in this area, given a large number of health workers have to commute on our services, for example to St Thomas's hospital, (the Guy and St Thomas's hospital trust employs approximately 19,000 staff) which is less than half a mile from London Waterloo [14].

Noting the timeline of COVID-19 outlined earlier in this report, SWR started to be concerned about the impact of COVID-19 early on in this crisis in February, with the initial assessment being that there would be a slight impact to the business in the form of increased absence figures. However, global case numbers continued to rise and there was significant media attention being devoted to pandemic coverage. The business established a dedicated command and control structure to be able to support a prompt and decisive approach to responding to COVID-19 in March. It should be noted that COVID-19 was being dealt with via existing business structures, but a strategic decision was taken by the SWR Executive to set up a dedicated structure. The outline structure of the SWR business structure to respond to COVID-19 is shown in Figure 3.

The gold level is where strategic decision making is undertaken in the business (e.g. HR policy), the silver level is where detailed work is undertaken, information is reviewed and ensures the strategic direction from the gold level is carried out by the bronze level components.

There are eight distinct directorates in SWR:

- Operations and Safety with a senior manager from within this Directorate initially chairing the response.

- Customer Experience

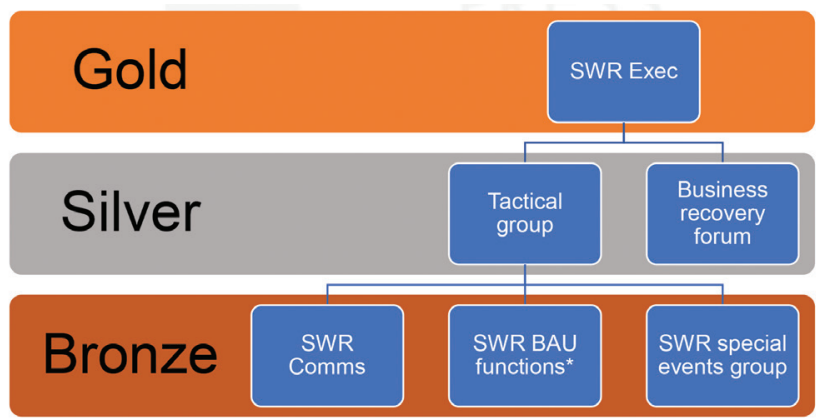

Figure 3 SWR COVID-19 command and control structure. "Business as usual' functions include e.g. safety, human resources, operations, guards, drivers.
- Performance and Planning

- Major Projects

- Engineering

- Commercial

- Finance

- HR

The SWR COVID-19 command and control structure outlined in Figure 3 has oversight of all of these directorates with respect to decisions that have to be taken related to the response to the pandemic.

Having distinct groups for dealing with the response is essential for managing the SWR response effectively. The gold level allows for any matters of company policy to be reviewed, discussed and agreed. The strategic intent of the SWR Executive can then be carried out by the tactical group at the silver level. The strategic intent underpinning the entire SWR response to COVID-19 is as follows:

(1) Keep customers and colleagues safe.

(2) Reassure customers and colleagues on the measures that are being taken.

(3) Promote examples of innovation across the business that support the response to COVID-19 and can be used to maximise long term business benefit.

Business leads from all areas of the business are represented at the tactical group. The business leads are senior managers in the business with the authority to be able to make prompt decisions. This tactical group also reviews important changes in UK Government policy and ensures that the business is compliant with the latest COVID-19 requirements.

This decision-making process has proven highly effective in ensuring the business is agile in responding to the challenges posed by COVID-19.

Additionally, while the command and control structure was established predominantly to aid decision-making, it also allowed for the efficient cascade of information across the business (importance of information cascade and effective communications will be expanded upon later in this paper).

At the silver level, there is also a business recovery forum. This allows for long term "over the horizon" matters to be discussed and also to ensure the business is agile enough for future requirements, e.g. timetable changes, passenger numbers etc.

For SWR a useful measure of the changes in the number of passengers on the network is the number of passengers arriving at London Waterloo in the morning. This represents one of the predominant flows of passengers into the UK's capital. For example, on a typical day before the first national lockdown, in the morning as opposed to between 0400 and 1000, approximately 125,000 passengers would arrive at London Waterloo. At the time of writing this paper the typical number is approximately 18,000 - a reduction of $85 \%$ [15].

The reduction over time is shown in Figure 4. 


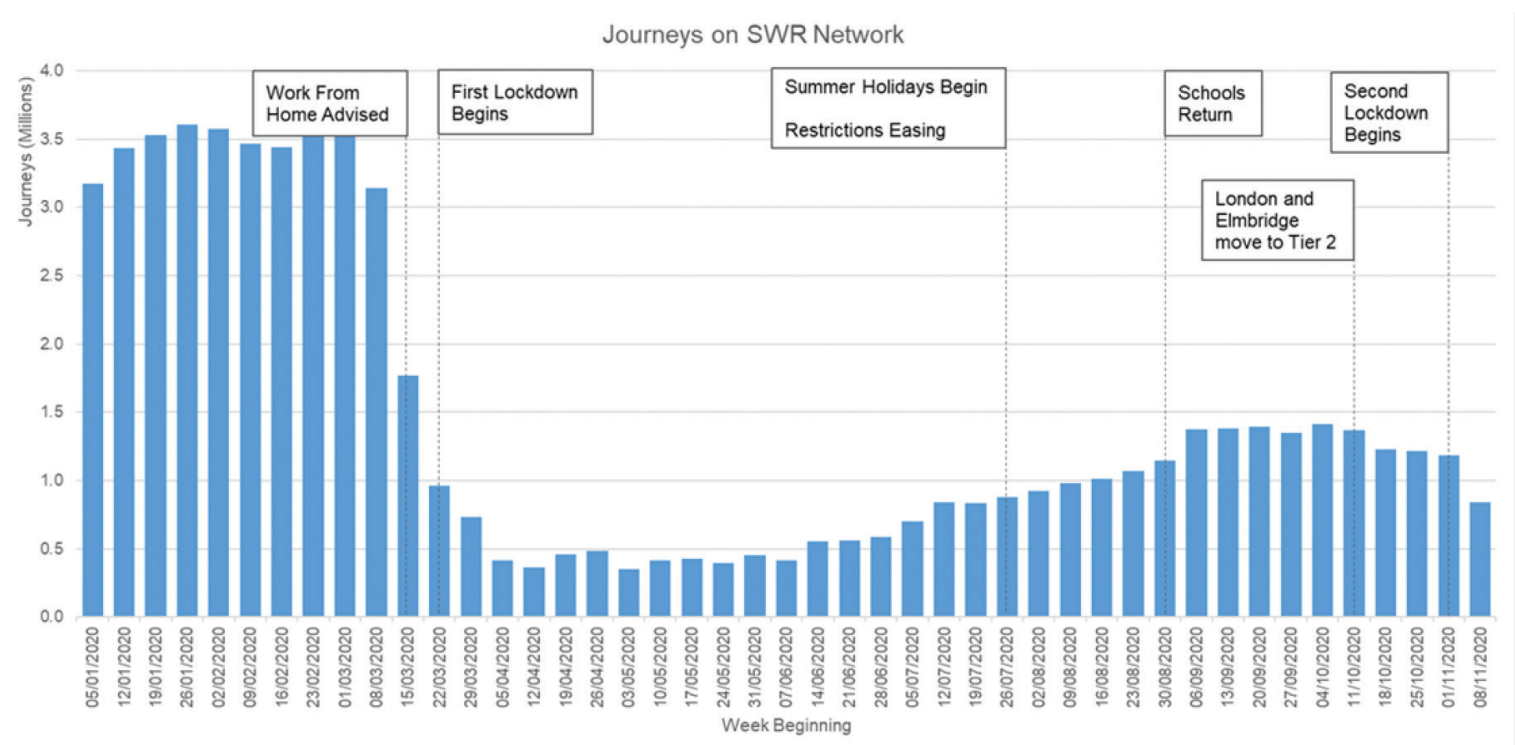

Figure 4 Number of journeys on the SWR network linked to key COVID-19 events [3-6].

The reduction in customer numbers has been caused by a combination of factors:

- UK Government stay at home message on 23 March 2020. This was a mandatory requirement from UK Government and subsequently the instruction was backed up with legislation.

- Post-lockdown UK Government restrictions: Even outside of a lockdown, there are still restrictions on individuals and businesses.

- Adaptation to working practices: It can be suggested that people have adapted to working from home. Businesses have been forced to adapt policies and procedures to facilitate this and to some extent this change has become entrenched in people's behaviour. The Chartered Institute of Logistics and Transport [16] reported in the summer that only $60 \%$ of London commuters would change the way they travel after lockdown restrictions were eased.

- Customer sentiment: Customers feel nervous about travelling due to a perceived threat of COVID-19. Studies have been undertaken across various forms of public transport to understand customer sentiment about travelling on public transport during the pandemic. At the time of writing, internal SWR reporting shows that (despite the cleaning measures introduced) a high proportion of customers are still nervous about travelling [3-6]. This report will highlight later in more detail what has been done across the business both in terms of actual safety measures, but also reassuring customers and SWR's own colleagues.

The command and control structure outlined previously has allowed the business to respond quickly to these changes. Not only is keeping customers safe a legal obligation, it is a moral obligation and if customers can sense that SWR is taking risk control measures seriously, they are more likely to feel confident travelling with SWR.

At the start of the pandemic, there were relatively simple requirements in place, however, a key requirement was to follow social distancing. The World Health Organisation [17] has made it clear that social distancing is a key defence against COVID-19. SWR has promoted social distancing (and other measures) by:

- Informing customers: All SWR trains have stickers reminding customers to keep their distance and additionally, automated announcements have been deployed to the SWR fleet, reminding customers of the requirements. On-train measures are replicated at stations and colleagues are requested to inform customers about the measures, noting however that they have no legal ability to enforce the measures. We have deployed approximately 50,000 vinyls, stickers and posters across our network and on our trains. A challenge with announcements is that customers over time become used to them. To overcome this, the business ran an internal competition for the children of colleagues to record announcements on social distancing. This proved highly effective, for customer compliance but also for colleague engagement as it refreshed traditional messaging. A screenshot from Twitter showing the campaign is shown in Figure 5.

- Linking social distancing capacity to the timetable: When the UK lockdown was announced on the 23 March, an emergency timetable was introduced that reduced the number of services to approximately $54 \%$ of a normal timetable. Given SWR operates a variety of different types of train, each with a different seating layout - social distancing capacities had to be fully assessed and linked back to the timetable, ensuring that the timetable being offered was supplying adequate capacity to achieve social distancing. This exercise was undertaken every time the business increased the timetable, in line with forecast demand and expected COVID-19 measures being relaxed by the UK Government. Timetable changes and the associated number of services relative to the December 2019 timetable (representative of full capacity) being offered are shown in Figure 6.

On some classes of stock, the social distancing requirement led to capacity being reduced by approximately $80 \%$.

- Hand sanitising: Customers are reminded to wash hands at regular intervals (by posters and announcements), but this will not always be possible, so the business has deployed hand sanitiser 
SWR Help @SW_Help ·Aug 12, 2020

C Congratulations to Evie and Teenasha - both children of SWR staff who won a competition to become the voices of two new station announcements.

F Listen out for Evie and Teenasha, who will be urging customers to stay safe.

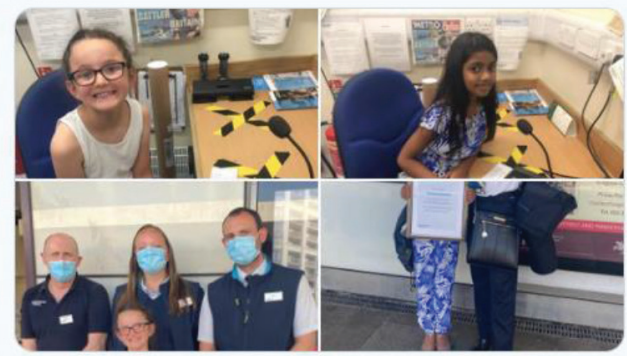

Figure 5 Screenshot from Twitter of colleagues' children announcement campaign.

\begin{tabular}{|l|c|}
\hline Timetable changes & $\begin{array}{c}\text { \% of services relative } \\
\text { to December 2019 }\end{array}$ \\
\hline $\begin{array}{c}\text { December 2019 baseline (being offered up until } \\
\text { the introduction of the UK Lockdown) }\end{array}$ & $54 \%$ \\
\hline $23 / 3 / 20$ & $59 \%$ \\
\hline $18 / 5 / 20$ & $68 \%$ \\
\hline $15 / 6 / 20$ & $79 \%$ \\
\hline $6 / 7 / 20$ & $82 \%$ \\
\hline $7 / 9 / 20$ & \\
\hline
\end{tabular}

Figure 6 Timetable changes linked to number of services.

dispensers to a large number of stations so customers are able to easily sanitise their hands.

- Face coverings: Prior to the start of the pandemic (and even after the start) the wearing of face coverings in the UK was not widespread. Recognising the benefits that face coverings have in (a) reducing the transmission risk from an infected individual and (b) reducing the risk of someone becoming infected, the UK Government made the wearing of face coverings compulsory on public transport in England on 15 June 2020 (but not yet stations). This change posed a unique challenge for the railway industry in the following ways:

- While the wearing of face coverings was compulsory on public transport (i.e. trains, buses etc.), it was not compulsory at railway stations. The industry largely remained neutral on this point, until the wearing of face coverings in enclosed public spaces was made a legal requirement in England on 24 July 2020. Noting that a substantial proportion of SWR's railway estate is not enclosed, for simplicity of public message, the business mandated the wearing of face coverings on all areas of stations.

- The wearing of face coverings for staff is not a legal requirement. SWR very quickly after the 15 June 2020 recognised this posed a challenge as public facing staff have a role to play in leading by example. SWR colleagues are instructed by the company to wear face coverings in all public settings.

- The role of colleagues: Under the various items of legislation around COVID-19, colleagues do not have the ability to enforce the wearing of face coverings, however, SWR has stressed the importance of educating and encouraging customers to follow the rules.

- Working with the BTP: The BTP are the law enforcement agency in the UK that polices the railway system, only they (and other police forces) have the ability to enforce the use of face coverings and SWR actively works with the BTP on ensuring suitable deployment of officers at areas where face covering compliance is poor.

- Messaging: Ensuring that the various legal requirements are conveyed across a range of channels, e.g. posters and announcements and highlighting the potential fine for non-compliance while ensuring that customers are not discouraged from travelling with overly threatening communications.

- Broadly speaking, compliance with rules on face coverings is approximately $90 \%$ across the network, but this can vary across the network.

- Train hygiene: A significant amount of work has taken place across SWR and FirstGroup/MTR in terms of understanding how to effectively clean trains to the best standard possible, not only to reassure customers but to minimise the risk of surface transmission of COVID-19. Some of the measures taken include:

- Turnaround cleaning: As much as is possible at locations where trains terminate, trains are cleaned before starting their next journey. This includes wiping down key contact areas and removing litter.

- Zoono: All trains are sprayed with a powerful sanitising virucide, Zoono Z71 which kills a very high proportion of viruses and bacteria (including COVID-19) and leaves a protective film on treated surfaces for a period of time. We also have a regime in place to ensure that trains are maintained within the effectiveness period of the chemical.

- Station hygiene: The work on the station estate largely mirrors what is done on trains. Stations are sprayed with Zoono 71. In addition, SWR has increased the frequency of cleaning at stations. SWR looks out for better ways of cleaning as part of wider COVID-19 innovation and horizon scanning.

A key priority for SWR has been ensuring colleague safety throughout the pandemic. At the start of the first lockdown in March 2020, the business (in line with UK Government requirements) minimised the amount of colleagues in the workplace, with those colleagues having office-based roles being instructed to remain at home. Laptops were given to as many colleagues as possible to allow working from home.

As lockdown restrictions eased in summer 2020, colleagues with office-based roles could return to the workplace, in a COVID-19 secure way. Measures deployed to keep colleagues safe included:

- Assessing every location: Each location was assessed to ensure social distancing, the number of colleagues permitted in enclosed meeting rooms was reduced and cleaning regimes and risk assessments were reviewed and enhanced as required. This work took place when the first lockdown started and the business was keen to be ready for restrictions easing.

- Desk booking: An in-house desk booking app was developed (screenshots shown in Figure 7) for the SWR Head Office in 


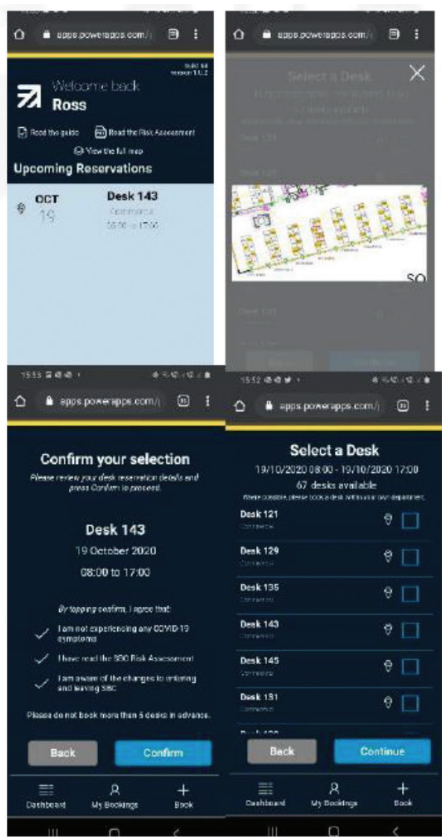

Figure 7 Screenshots of SWR desk booking app.

London in September 2020. The app allows colleagues to reserve a desk, using a map within the app which factors in the social distancing of desks.

- Hygiene hooks: In summer 2020 each colleague has been issued with an SWR branded hygiene hook (example shown in Figure 8) which removes the need for direct contact with surfaces such as door handles, ATM buttons and train door buttons. While these do not replace good hand hygiene, they are still effective and have assisted with colleague engagement.

- Clinically vulnerable and clinically extremely vulnerable colleagues: Up until August 2020, colleagues that were deemed by the UK Health Authorities as being "clinically extremely vulnerable" were advised to remain at home, but since England entered a second lockdown, these colleagues have been advised again to remain at home. Colleagues that are deemed to be "clinically vulnerable" are permitted to be in the workplace and individual risk assessments are being completed for those individuals.

- Outbreak management: In England, an outbreak is deemed as any two or more COVID-19 positive tests at a single location. SWR has a robust process for dealing with any COVID-19 case. This involves each case being assessed and a 'lessons learned' exercise undertaken as required to understand how the colleague contracted COVID-19 and if anything else can be done to improve safety.

- Reminding colleagues of the basics: Regardless of the measures the business is putting in place to keep colleagues safe, colleagues are continuously reminded that one of the biggest barriers that can prevent them from getting COVID-19 is through their own actions.

- Face coverings: As was previously outlined in this report, it is not a legal requirement for colleagues to wear face coverings, but, the business has made it a mandatory requirement for colleagues to wear face coverings in public areas, or as required when determined by a task based risk assessment. There are a small number of colleagues who are exempt from wearing face coverings, due to pre-existing and long standing medical health conditions (e.g. respiratory problems) and as such the business introduced (in summer 2020) a process for assessing these colleagues and if needed they are issued with an exemption lanyard as shown in Figure 9.

While (like any business), SWR's absences has been largely determined by the prevailing national situation, there is no evidence to suggest that the absence levels experienced in March 2020 will be experienced again, largely in part due to the measures the business has introduced to keep colleagues safe as a result of the learning from the first wave. The graph in Figure 10 below shows the overall percentage absence over time.

The peak of COVID-19 related absences was reached on 30 March 2020 when $12.81 \%$ of the SWR workforce was absent due to the pandemic and at the time of commencing this report, the business is experiencing a typical daily COVID-19 absence figure of approximately $2.4 \%$, which is under the industry average [3-6]. The reasons underpinning this significant reduction are due to:

- Business confidence: The business is much more confident in dealing with COVID-19 and working with colleagues to ensure they are confident to be in the workplace.

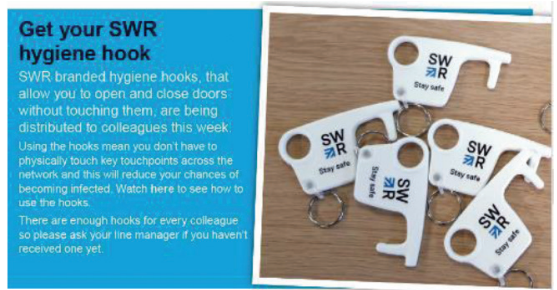

Figure 8 SWR hygiene hooks.

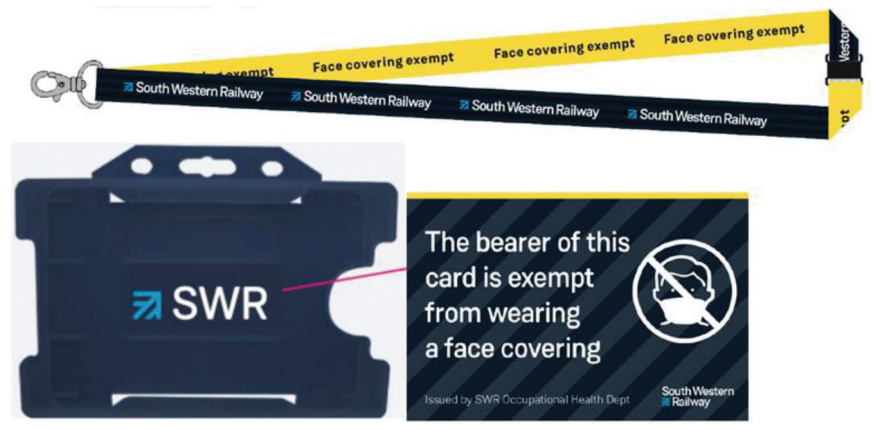

Figure 9 SWR exemption lanyard and badge.

Absence covid related in percentage terms

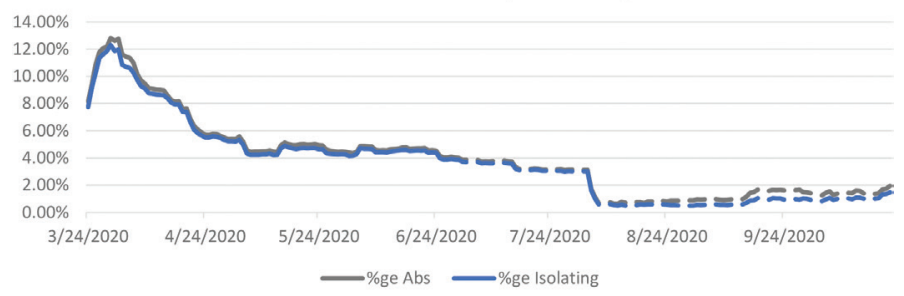

Figure 10 Graph showing SWR COVID-19 absence [3-6]. 
- Colleague confidence: Linked to the previous point, the business is doing whatever is possible to communicate to colleagues about what the business is doing to keep them safe.

- Business learning: The business knows a lot more about the virus, e.g. by talking with MTR Hong Kong and how to respond.

- Practical measures to combat the virus: First and foremost the business has introduced lots of different measures to combat the virus, introduced 'post outbreak reviews' and shares learning across the business if an outbreak is experienced.

- Challenging health authorities: There have been some instances where the business has challenged relevant health authorities where it was felt that colleagues were being told to remain at home without reason. For example, this approach was highly successful at one of our major stations when 14 colleagues were instructed to remain at home, but through engagement with the relevant health authority, 12 of those colleagues were allowed to return to the workplace.

Communicating with customers and colleagues throughout the pandemic has been vital throughout and effective communication by SWR has been used to do the following:

(1) Reassure our customers and colleagues about the measures the business is taking to keep them safe.

(2) Remind customers and colleagues about what they can do to influence their own safety in relation to COVID-19 and the legal requirements that they must follow.

(3) Seek feedback from customers and colleagues about the business's response to COVID-19 to assess its effectiveness and promote continuous improvement.

With regards to communicating with customers, the business has a communications group that meets every weekday, to consider COVID-19 as well as routine business. The operational decisions for the business are reviewed and decided at the tactical group and then the communications group considers how to effectively communicate the messages to customers, for example:

- Fines relating to face coverings: The fines customers can be issued by the police has gradually increased throughout the pandemic and the communications group has had to assess posters, announcements and social media interaction in an attempt to influence customers into following the requirements, while ensuring they are not discouraged from travelling with SWR.

- Reassurance for customers: Highlighting what the business has put in place to keep customers safe, so that we can make them feel safe when travelling. This has largely been achieved by social media and posters at stations and on trains, examples shown in Figures 11 and 12 .

- Understanding current customer perceptions: The business undertakes its own customer surveys and also uses industry data to understand how customers perceive SWR's response to COVID-19. This intelligence is subject to ongoing review to understand what more can be done to reassure customers.

SWR has considered crisis communications around COVID-19 essential for the following reasons:

(1) Safety and procedures: If colleagues are not kept up to date with the various company and legislative requirements, they might not be adequately protected against COVID-19.

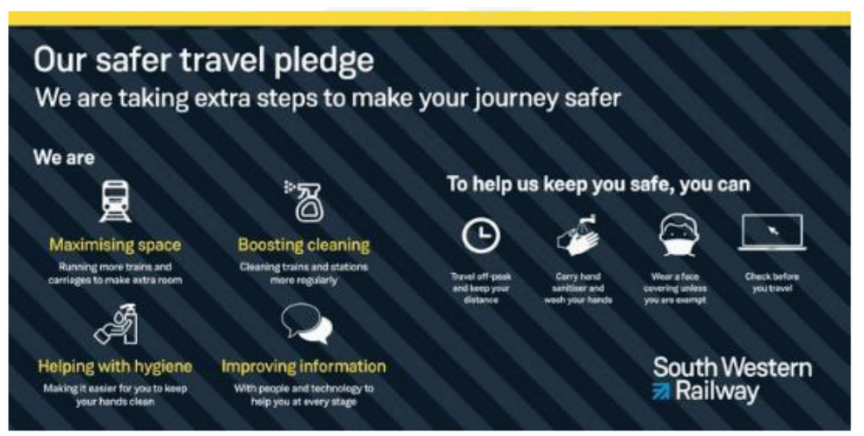

Figure 11 SWR safer travel pledge.

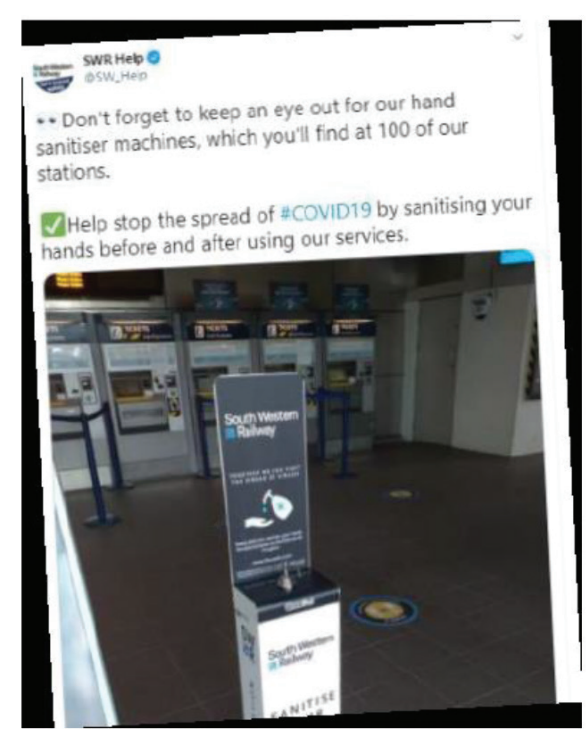

Figure 12 SWR hand sanitiser.

(2) Builds trust: Crisis communications with SWR colleagues has always aimed to be frank and honest, showing the company is not hiding anything from its colleagues. If colleagues trust an organisation through its communications, they are likely to be more effective in their role and the importance of this in a customer facing organisation such as SWR is even more important.

(3) Removes uncertainty: Uncertainty can be extremely unpleasant for colleagues and SWR has attempted to remove this uncertainty with regular communications across a number of channels, including:

- Regular emails updating colleagues

- Weekly colleague newsletters

- Management video calls

- Face to face interactions in a COVID-19 secure way

South Western Railway embraced video technology early in the pandemic. Fortnightly video calls are held with the senior leadership team to communicate the COVID-19 strategic level response allowing them to effectively communicate it to the managers they are responsible for. Additionally, a fortnightly all manager video call is held, involving 300-400 managers, to communicate details of the latest COVID-19 response. 
While the general management of day-to-day COVID-19 activities has been a challenge, there have been a number of additional matters that have required extra resource and planning:

(1) Schools and colleges September return: The vast majority of schools and colleges were closed in March, except to the children of key workers. The business recognised that many pupils would not have travelled by train since March and therefore extra measures should be put in place. A dedicated schools and colleges command and control group was set up, with individuals from key business areas and this group considered and dealt with the following:

- Building up intelligence: A list of when the various educational institutions were returning and what railway stations they fed into was established to determine what the social distancing capacity of these stations would be and key services required.

- Putting in place operational plans: Where required SWR recruited additional agency staff to assist with crowd control and educating pupils on the COVID-19 requirements.

- Understanding the timetable: Noting that the timetable being offered did not offer as much capacity as the previous pre-COVID-19 timetable, a detailed review was undertaken of what was being offered and any gaps in the service were filled to ensure pupils could get to school/college safely.

- Communicating: A dedicated team of managers directly contacted key educational institutions on the SWR network, requesting that they remind parents, staff and pupils of the COVID-19 safety requirements (face coverings and social distancing), additionally SWR used its website and social media channels to directly appeal to parents and pupils (campaign shown in Figure 13), asking them to plan ahead and travel safely.

- Daily command and control: Twice daily meetings took place in the immediate run up to and post school/college return, to react to any issues that were not previously foreseen, gather further intelligence and put in place any new mitigations.

The measures that have been outlined proved highly effective in managing the return.

(2) University Christmas departure: At the time of writing this report, the UK Government has stated that it requires students in England to travel home between 3 and 9 December. The business has reactivated the schools and colleges command and control group for this challenge as large numbers of students with large amounts of luggage are expected to travel during this window. While the challenge is not on the same

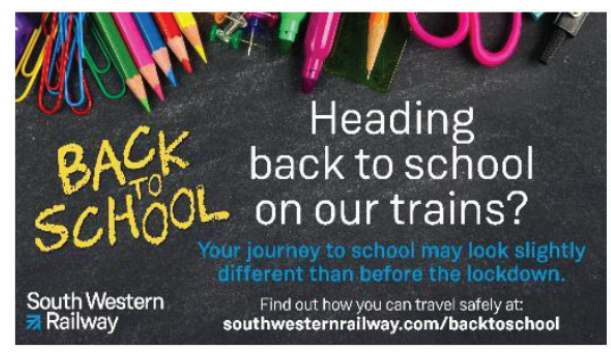

Figure 13 SWR back to school campaign. scale as the challenge experienced in September, the group within SWR dealing with this challenge is considering:

- Understanding key dates, routes and locations relevant to student passengers. Sources of passenger data being used include use of the UK 16-25 Young Persons Railcard.

- Contacting universities directly to understand when their students will be departing.

- Putting in place operational plans and additional staff to support students travelling.

\section{LOOKING AHEAD}

To ensure the business is not just dealing with the 'here and now' via the tactical group previously outlined in this report, the business has a business recovery and over the horizon group to consider the following:

- Threat scanning: Identify future business threats from COVID-19, to ensure business structures, processes and procedures are in place to be able to respond in advance of the threat arriving.

- Develop an understanding of what business processes are not operating normally because of the pandemic and then putting in place plans to return them to normal operation as far as is possible.

- Readiness reviews: Undertaking readiness review processes for key events, e.g. timetable changes and ensuring all business plans are in place, with a particular focus on COVID-19 requirements, e.g. social distancing considerations with having additional colleagues in the workplace to support these uplifts.

- Innovation: The COVID-19 pandemic has resulted in a unique opportunity to review all business processes and how they can be simplified. For example, the desk booking app that was referred to earlier in this report has shown what can be achieved and the business is actively looking for further opportunities to digitise company processes, e.g. COVID-19 related absence reporting.

The business has introduced more robust business assurance processes, including:

- Independent auditing: All SWR locations are subject to random and unannounced audits at any time by the SWR Safety Function with a focus on:

- Social distancing measures: e.g. posters and signage.

- Access to hand sanitiser.

- Colleague compliance: Review colleague compliance with regards to COVID-19 requirements.

- Risk assessments.

- Remedial measures: What measures may be required to improve the level of COVID-19 safety at a particular location.

- Wider business learning: Reviewing what examples can be shared with the rest of the business.

- Self-auditing: As above but local managers are required to undertake this every month at the location they are responsible for. 
- Safety tours: FirstGroup has a Group-wide process for recording safety visits undertaken by any managers and they are being instructed to specifically focus on COVID-19 measures.

At the time of writing, the UK is in a second wave, with high numbers of daily cases (as shown earlier in this report) and areas of the whole country under various lockdowns. The second national lockdown affecting England was relaxed on the 2 December 2020, at which point the nation returned to a local system of restrictions and then subsequently a new national lockdown on 5 January 2021. SWR anticipates that a relaxation of the current national lockdown will see an increased customer demand and the business will monitor this, in particular to ensure adequate social distancing capacity across the network. Various releases in the media have conveyed positive news about vaccines. Key considerations for SWR will include:

- HR policies in relation to the vaccine.

- Supporting the anticipated mass vaccination campaign at SWR locations, e.g. station car parks.

- Demand will increase even further and uncertainty as to whether social distancing and face coverings will continue to be a long term requirement.

\section{CONCLUSION}

This report has met its objective of giving an overview of the effectiveness of the SWR response to the pandemic, while demonstrating how the business has ensured high levels of both customer and colleague safety, which was made challenging at the start of the pandemic, due to the previously low level of awareness across the UK about COVID-19.

Customer demand has been significantly reduced and comment has been provided on the long-term forecast for demand. While the news on the various vaccines is welcome, SWR does not expect demand to return to previous levels for some time, particularly as there is evidence and reports that businesses and individuals have learned to adapt to working from home.

In terms of how SWR has responded to the pandemic so far in comparison to other train operators, it can be surmised that the business has responded relatively well, SWR has managed to maintain a service across the majority of its routes throughout and has had a COVID-19 absenteeism figure that compares favourably to other train operators.

A view from the SWR Commercial Director Peter Williams on the SWR response is detailed below (R Liddell 2021, personal communication, 5 February):

The COVID-19 pandemic has posed significant challenges to businesses' and individuals alike. With no previous experience of a challenge of this nature we were very much aware of the steep learning curve we were facing, and that we needed to put in place a decision making and communication process that would enable us to implement the Government's requirements without delay. In this respect the gold/silver/bronze command and control approach played a vital role in ensuring that responsibilities were allocated to the appropriate management teams in the business, and that everyone knew the role they had to play.
A feature of the pandemic has been the need to quickly respond to the latest Government requirements on a wide variety of policy areas including travel restrictions, social distancing, face coverings etc. The approach we adopted enabled us to assimilate the requirements, identify the implications for our working practices and provide timely updates to our customers through a variety of channels including station posters and information systems, on train announcements and social media. This method of working has been successful and is reflected in the positive feedback we have received from a range of industry stakeholders.

At all times we sought to be open to new ideas rather than necessarily rely on established practices. For example, in summer 2020 when restrictions were being eased and some colleagues were returning to our offices we developed and launched a desk booking app for our head office that ensured social distancing was maintained between work desks and that the reduced headcount limit was never breached. Additionally, we looked at what else we could do help ensure the safety of our staff and even issued all colleagues with an SWR branded 'hygiene hook' which removes the need for direct contact with surfaces such as door handles and train door buttons.

While many of the challenges of the pandemic remain the approach we have taken, incorporating a feedback loop, ensure that we are able to adapt and seek continual improvements for the benefit of our customers and colleagues.

The UK is currently in a second wave of COVID-19 and SWR like all other businesses has been affected by this second wave, but fundamentally the learning gained from dealing with the first wave of COVID-19 has been used to inform ongoing planning and decision making. The business has introduced a specific command and control structure adapted to respond to COVID-19, specific reporting structures and enhanced safety measures for reducing the risk from COVID-19.

The UK Government has stated repeatedly the importance of rail in keeping the UK operating and SWR anticipates passengers continuing to return to the network.

\section{CONFLICTS OF INTEREST}

The author declares no conflicts of interest.

\section{ABBREVIATIONS}

CBI, Confederation of British Industry; NR, Network Rail; SWR, South Western Railway; TOC, Train Operating Company; WHO, World Health Organisation; WSP, Willams Sale Partnership Limited.

\section{REFERENCES}

[1] Confederation of British Industry. Commuting beyond the coronavirus. 2020. Available from: https://www.cbi.org.uk/media/5101/ cbi-kpmg-commuting-beyond-the-coronavirus-july-2020-final-1. pdf (accessed November 18, 2020). 
[2] WSP. Rail and the effects of the COVID-19 pandemic. 2020. Available from: http://cdn.wsp-pb.com/415648/swedish-whitepaper-rail-and-the-effects-of-the-covid-19-pandemic.pdf (accessed November 11, 2020).

[3] South Western Railway. COVID-19 absences Internal SWR data. 2020. Unpublished.

[4] South Western Railway. COVID-19 HR data. Internal SWR data. 2020. Unpublished.

[5] South Western Railway. Customer sentiment research. Internal SWR data. 2020. Unpublished.

[6] South Western Railway. Passenger Count Data. Internal SWR data. 2020. Unpublished.

[7] British Broadcasting Corporation. Coronavirus: deaths at lowest level since March. 2020. Available from: https://www.bbc.co.uk/ news/health-52890515 (accessed November 14, 2020).

[8] British Broadcasting Corporation. Coronavirus: Leicester 'could be locked down' says home secretary. 2020. Available from: https:// www.bbc.co.uk/news/uk-england-leicestershire-53206506 (accessed November 14, 2020).

[9] British Broadcasting Corporation. Coronavirus: test and trace system kicks off in England and Scotland. 2020. Available from: https:// www.bbc.co.uk/news/uk-52829357 (accessed November 14, 2020).

[10] British Broadcasting Corporation. Coronavirus: two cases confirmed in the UK. 2020. Available from: https://www.bbc.co.uk/ news/health-51325192 (accessed November 12, 2020).
[11] United Kingdom Government. The next chapter in our plan to rebuild: the UK Government's COVID-19 recovery strategy. 2020. Available from: https://www.gov.uk/government/publications/ourplan-to-rebuild-the-uk-governments-covid-19-recovery-strategy/ the-next-chapter-in-our-plan-to-rebuild-the-uk-governmentscovid-19-recovery-strategy--2 (accessed November 13, 2020).

[12] United Kingdom Government. Coronavirus (COVID-19) in the UK. 2020. Available from: https://coronavirus.data.gov.uk/ details/cases (accessed November 13, 2020).

[13] Sherratt P. Franchises move to emergency measures. Mod Rail 2020;77:8.

[14] National Health Service. Facts and figures. 2020. Available from: https://www.guysandstthomas.nhs.uk/about-us/who-we-are/ facts-figures.aspx (accessed November 22, 2020).

[15] Network Rail. Waterloo Passenger Count Data. Internal NR data. 2020. Unpublished.

[16] The Chartered Institute of Logistics and Transport. COVID-19 anxiety changing travel habits. 2020. Available from: https://ciltuk. org.uk/News/Latest-News/ArtMID/6887/ArticleID/29250/ COVID-19-anxiety-changing-commuter-travel-habits (accessed November 14, 2020).

[17] World Health Organisation. Coronavirus disease (COVID-19) advice for the public. 2020. Available from: https://www.who.int/ emergencies/diseases/novel-coronavirus-2019/advice-for-public (accessed November 12, 2020). 